\section{Refugee fences fragment wildlife}

Erecting border fences in parts of Europe in response to the current massive influx of refugees may harm wildlife. The fences can kill animals by entangling them in razor wire and will jeopardize the hard-won connectivity of species populations.

The human toll of the refugee crisis deserves the highest political attention. At the same time, many of the fences could be in violation of commitments under international conservation agreements, such as the European Commission's Habitats Directive.

With the opening of political borders during the twentieth century, Europe's large fauna have rebounded. This success is a result of trans-boundary conservation projects backed by legislation and effective management.

However, refugee fences have proliferated along the borders of Slovenia, Croatia and Hungary, for example, and more are planned along the boundaries of Latvia and Estonia with Russia. These are likely to affect brown bear, wolf, lynx and red deer species.

Mitigation measures should include adapting national conservation-management schemes to ensure the survival of newly isolated animal populations; designing the structure and placement of fences to minimize their impact on wildlife; and removing the fences at the earliest opportunity. John D. C. Linnell ${ }^{\star}$ Norwegian Institute for Nature Research, Trondheim, Norway. john.linnell@nina.no ${ }^{*}$ On behalf of 4 correspondents (see go.nature.com/fm6aaa for full list).

\section{Treat wasting illness on multiple fronts}

Cachexia is a complex wasting syndrome that cannot be fully reversed by nutritional support alone (see, for example, Nature
528, 182-183; 2015). There is accumulating evidence that a comprehensive multimodal approach may succeed where unimodal treatments (such as nutrition or anabolic drugs) have failed to deliver extended clinical benefits. Support for a multimodal policy comes from established rehabilitation programmes (see, for example, M. A. Spruit et al. Am. J. Respir. Crit. Care Med. 188, e13-e64; 2013).

The failure of the classical unimodal approach suggests that a shift in clinical-trial design is needed (K. C. H. Fearon et al. J. Cachexia Sarcopenia Muscle 6, 272-274; 2015). This could include monitoring the combined effects of exercise and nutrition, along with controlling metabolism and systemic inflammation. These interventions would need to be tested early, before cachexia becomes irreversible.

The complexity of such interventions makes them difficult to organize and fund. They would require input from research, government, pharmaceutical companies and regulatory authorities. However, the possible clinical benefits stand to improve the quality and, in the long term, perhaps even the quantity of patients' lives.

Kenneth Fearon University of Edinburgh, UK.

k.fearon@ed.ac.uk

Competing financial interests declared; see go.nature.com/npxkyg.

\section{EU conservation overlooks geology}

The European Commission needs to expand its conservation policy to protect its seriously threatened geological heritage.

Legislation for nature conservation in the European Union has so far focused mainly on biodiversity and habitats (see, for example, V. Hermoso Nature 528, 193; 2015). But fossils, rocks, minerals and landforms also contribute to a country's geological landscape and heritage. Their features are a scientific asset that is shared by all countries, as well as an educational and cultural resource. They are also essential for supporting services to biodiversity. For example, geological sites in coastal cliffs and rocky outposts harbour and protect huge varieties of sea birds.

Neither of the two EU conservation directives that are currently under review (see go.nature.com/vkm9r7) includes the non-living elements of natural heritage, making it hard to encourage public respect for important geological features.

José Brilha European Association for the Conservation of Geological Heritage (ProGEO); and University of Minho, Braga, Portugal. jbrilha@dct.uminho.pt

\section{Plans for European medical doctorate}

I agree with Stefan Hardt and colleagues on the benefits of a unified European medical doctorate (Nature 528, 333; 2015). However, removing the research component to create a vocational degree could result in a shortage of clinician scientists.

This is evident from our (unpublished) 2014 survey of 1,069 supervisors of dissertations at Charité in Berlin, one of Europe's largest university hospitals. Just under $1 \%$ of 3,714 research projects were of an MD-with-PhD type, more than two-thirds were $\mathrm{MD}$ projects and the rest were straight $\mathrm{PhDs}$ and dental or nursing projects. Thus, shifting to a purely vocational European medical doctorate system would mean many physicians missing out on useful research training (see also D. M. Milewicz et al. J. Clin. Invest. 125, 3742-3747; 2015).

One solution might be to integrate the European medical doctorate into the medical curriculum. This would also encourage more-consistent application of evidence-based medicine in daily practice throughout the European Union (see J. Hilgers et al. Med. Teach. 29, 270-275; 2007). Formal training of lecturers, tutors and supervisors responsible for this integration would help to standardize and improve the quality of dissertation supervision (see Nature 527, 7; 2015).

Marc Dewey Charité - University Medicine Berlin, Germany. dewey@charite.de

\section{Monitor safety of aged fuel pipelines}

Ensuring the integrity and safety of old pipelines that transport oil and natural gas calls for frequent inspections, together with modern, sensitive leak-detection tools and regular removal of accumulated deposits.

The failure of old pipelines is becoming increasingly common, and can be dangerously disruptive to communities and the environment. Examples from the United States include the rupture in 2010 of a 41-yearold oil pipeline in Michigan, which spilled around 4.5 million litres of oil into the Kalamazoo River, and the 2013 failure of a 65-year-old pipeline in Arkansas, requiring 22 homes to be evacuated.

Modern pipelines built from high-quality steels are statistically safer than transporting such fuels by road or rail (J. Behar and S. Al-Azem World Pipelines 15 (4), 18-28; 2015). However, over half of US underground pipelines are more than 50 years old (see go.nature.com/gczd6b). Such aged pipelines could fail at any time from corrosion, cracking or coating deterioration (X. Li et al. Nature 527, 441-442; 2015). Frank Cheng University of Calgary, Alberta, Canada. fcheng@ucalgary.ca 